\title{
Luanda, camarada, Luanda...
}

\section{Andrea Cristina Muraro*}

\begin{abstract}
Resumo: Este trabalho analisa os tópicos espaço e Abstract: This work analises the topics space and discurso poético, nas obras angolanas Quem me dera poetic speech on the angolan novels Quem me dera ser ser onda (1982) de Manuel Rui e Bom dia camaradas onda (1982), by Manuel Rui and Bom dia camaradas (2000) de Ondjaki. (2000), by Ondjaki.
\end{abstract}

Palavras-chave: Espaço; Discurso; Manuel Rui; Keywords: Space; Speech; Manuel Rui; Ondjaki; Ondjaki; Luanda Luanda

Aos escolhermos duas narrativas angolanas, ambas traduzidas em diversas línguas e sucessivas edições em vários países, para o corpus deste texto: Quem me dera ser onda $(1982)^{1}$ de Manuel Rui Monteiro e Bom dia camaradas (2000) ${ }^{2}$ de Ondjaki, observamos que elas convergem, por meio do discurso, os protagonistas fazem a palavra 'camarada' circular, deambular e inocular um intricado jogo ideológico (BAKHTIN, 1999) postados em um espaço comum, a cidade de Luanda.

Mesmo que tenham sido produzidas em momentos diferentes: QMDSO na ambiência dos anos 80 e BDC do ponto de vista memorialista do narrador-protagonista, nota-se nelas o 'fato poético' concentrado naquilo que é seu 'projeto político', ou seja, o 'rompimento do signo lingüístico', internalizado na enunciação (cf. BAKHTIN, 1999, p.16) dos protagonistas que deambulam por Luanda, através da palavra 'camarada' (cf. CUNHA, 1986, p.142). Na etimologia desta, temos a argamassa de seu processo histórico - uma 'sobreposição de temporalidades': a 'câmara', o espaço em que se guarda e se cria, pelo contato com outros da relação, um valor internalizado de 'comunitarismo', nesses dois autores de gerações distintas, mas que "constituem um labirinto e procuram as suas saídas do ponto de vista utópico como elevação" (ABDALA, 2003), de um olhar muitas vezes cinematográfico, de câmera, daquilo que é o processo literário.

\footnotetext{
* Doutoranda em Estudos Comparados de Literaturas de Língua Portuguesa, FFLCH-USP, Mestre em Literatura e Crítica pela PUC-SP. Correio eletrônico: a.muraro@uol.com.br

${ }^{1}$ Ao longo do corpo do texto será usada a abreviatura QMDSO e a edição brasileira de 2005.

${ }^{2}$ Ao longo do corpo do texto será usada a abreviatura BDC e a edição angolana, de 2000.
} 


\section{Marejando olhos de câmera}

Em Quem me dera ser onda, o enredo inicia-se quando o pai dos protagonistas leva um porco para engordar no apartamento em que a família mora em Luanda; os meninos Ruca e Zeca, a partir daí, transformam o ilustre visitante, que vem sanar as carências alimentares na capital angolana, em um animal de estimação, passam a inventar artimanhas para que os vizinhos do prédio - espécie de micro-Luanda dos anos 80 - funcionários públicos, oficiais, vendedores, membros do MPLA não percebam a presença do porco. Também são responsáveis por alimentá-lo com restos colhidos pela cidade, principalmente dos fundos de um hotel e ao mesmo tempo articulam possíveis formas para evitar a morte de 'Carnaval da Vitória', nome dado ao porco como referência à data marcada para seu abate, durante o feriado cívico angolano com o mesmo nome e que data o epílogo da narrativa ${ }^{3}$.

É importante esclarecer que o teor da enunciação, por meio das vozes dos moradores do prédio, incide para a sátira do discurso político vigente no período:

- Eu é que estou a fazer? Eu que nem tenho maka ${ }^{4}$ com porco. Ele é que está a fazer tribalismo. E com porco. Só porque é meu. Tribalismo! Deixa lá de ismos, mulher, que isto não enche a barriga. Isso é peixefritismo, fungismo e outros ismos da barriga da gente. E tribalista é quem combate os ismos da barriga do povo, como esse Faustino. É por isso que isto não anda pra frente e eu é que devia falar na rádio e não esses berenguéis simonescos ${ }^{5}$. Era mesmo no meio dos relatos de futebol que eu ia falar panquês ${ }^{6}$, e ismos da barriga. É só peixe frito e paleio - e arrotou. (RUI, 2005b, p.4-5)

Muitas vezes, as vozes das crianças- protagonistas tendem a erguerem-se da borda marítima do mapa kaluanda, em meio a burocracia e a desilusão dos adultos, a narração ganha um certo lirismo,

Ali defronte, abriam-se aos olhos de Ruca as vagas que rebentavam lá em baixo. 'Sim, vão matar'. Que mistério era aquela grandeza de espuma branca, eriçando o mar?

- Vocês não gostavam de ser onda?(RUI,2005b, p.54)

Outras vezes, a tensão instaura-se, desmascarando os discursos instituídos e pode-se vislumbrar a sobreposição de várias Luandas, a dos tempos coloniais e dos tempos marxistas,

\footnotetext{
3 “aquele era o Carnaval da Vitória porque a 27 de março se comemorava o dia em que as forças armadas tinham expulsado o último sul-africano de solo angolano" in.: ONDJAKI. Os da minha rua.. Lisboa: Caminho, 2007, p. 50.

${ }^{4}$ Problema, conflito, confusão.

${ }^{5}$ De Simons, conhecido radialista angolano.

${ }^{6}$ Comidas.
} 
Então por que é que o tal ministro não manda comprar os porcos das províncias e pôr carne nas bichas de Luanda? Matadouro o tuga deixou. Vejam só: um povo revolucionário como o de Cuba tem a mesma opinião, come bué de carne de porco. (RUI,2005b, p.47-8)

Apesar do fato ser irônico, esta obra de Manuel Rui (2005b) foi agraciada com o Prêmio Camarada Presidente Agostinho Neto, em uma fase do regime (oficialmente marxistaleninista) em que a vigilância doutrinária era rigorosa e ensinada,

Os coordenadores do centro de investigações pedagógicas parou de mascar a lasca de cola. Cada um dos participantes da reunião não escondia a surpresa.

- Acho que pode tratar-se de um caso de inadaptação. Filho de um casal lumpen, por exemplo...- referiu a responsável pela secção de pedagogia.

_ Mas como é possível? Se foram dadas as directrizes quanto aos temas? - considerou o coordenador. _ Não se compreende. Se no ofício eram orientados no sentido de motivarem as crianças para escreverem sobre os problemas do povo, exaltação dos valores ideológicos, etc., como é que a professora escolhe para um concurso deste nível uma redacção sobre um porco? Camarada Sofia, já agora descubra ... (RUI,2005b, p. 30-1)

Tal professora assistiu à festa feita pelas crianças, em dias anteriores, quando o porco visitou o pátio da escola, provocando uma apoteose ao escapar à roda de meninos e singrar pelas ruas de Luanda. No espaço público da escola, a professora responde a uma convocação sobre as redações de um concurso, seus olhos estão fiscalizados pela máquina estatal, mas carregam o sinal da utopia metaforizada em mar:

- Sim. - nos olhos da professora alindou-se uma onda de orgulhosa alegria - Antes que me esqueça, os alunos propuseram e votaram todos a favor que a nossa escola passasse a chamarse 'carnaval da vitória'(RUI, 2005b, p.39)

\section{Escrevendo de dentro da câmara}

A escola, em ambas as obras, é um espaço deflagrador e multiplicador dos mais variados textos e contextos deste discurso político-poético, em que uma voz intratextual tornase uma personagem que fala no mapa de Luanda, através de hinos, cartazes, escritos em paredes, como podemos verificar a seguir em dois excertos, a cerca das redações produzidas na escola,

(...) porque a luta continua e o responsável da comissão de moradores não sabe as palavras de ordem que os pioneiros é que lhe ensinam. E a camarada professora é muito boa porque deixa fazer redacções que a gente quer (...) (RUI,2005b, p. 30)

Acordei cedo e muito bem disposto. Tinha duas coisas maravilhosas para fazer nesse dia: uma é que ia ao aeroporto buscar a tia Dada, a outra é que ia à Rádio Nacional ler minha mensagem para os trabalhadores. Pensei que seria bom aproveitar umas coisas da redacção que eu tinha feito sobre a aliança operário-camponesa, que tinha tido cinco valores na prova de Língua Portuguesa.(ONDJAKI,2000, p.35) 
Embora Bom dia Camaradas privilegie a escola como espaço durante boa parte da narrativa, a obra inicia-se - assim como Quem me dera ser onda - a partir de um espaço familiar: a casa -fração terrena deste mapa- em que o narrador mora com os pais e as irmãs. Ondjaki (2000) parece preferir os risos e cheiros que compõem rostos e espaços de suas personagens, sem deixar de lado os mujimbos ${ }^{7}$ as estigas $^{8}$, tão peculiares à cultura angolana aos atropelos e gritos dos pais de Zeca e Ruca.

O enredo de Bom dia Camaradas é guiado por um narrador (quase) adolescente que tateia a presença dos cubanos na educação, portanto, na escola - através do cotidiano de um grupo de crianças que cresce aos preceitos da revolução, guerrilha, cartões de abastecimento e monopartidarismo. O fio condutor é centrado nos preparativos para uma visita-surpresa do inspetor escolar e um mujimbo que se espalha entre as crianças sobre um grupo de gregos ${ }^{9}$ denominado ‘Caixão Vazio', que supostamente invadirá a escola.

\section{Acamaradando escritas}

As peripécias das crianças somadas à abordagem dada à presença cubana já seriam o suficiente para considerar BDC como obra de exceção e constituir-se como continuidade ao sistema literário angolano, ao lado de QMDSO.

E para situarem-se neste sistema, uma das estratégias de enredamento utilizada pelos autores é inscrever-se através de construções intratextuais como as redações já comentadas ou em referências a N'gola Ritmos, Cadornega, Carlos Buriti, Che Guevara, insinuadas na enunciação de algumas personagens, o que é mais comum no caso de Manuel Rui (2005b). Já em BDC, a estratégia é utilizar-se de construções extratextuais em paratextos, embora Ondjaki também fisgue do próprio Quem me dera ser onda a expressão "verzul” (ONDJAKI, 2000, p.59) e aponte a água como leitmov, é preenchendo espaços metalingüísticos como o da epígrafe que o diálogo se estabelece: Ondjaki troca a palavra aurora do poema de Drummond para Angola,

E tu, Angola:

'sob o úmido véu de raivas, queixas e humilhações, adivinho-te que sobes, vapor róseo, expulsando a treva noturna'. (ONDJAKI, 2000, p.01.)

\footnotetext{
${ }^{7}$ Boato, fofoca.

${ }^{8}$ Ridicularizar outrem através de um criativo e bem-humorado jogo de palavras.

${ }^{9}$ Delinqüentes.
} 
Outro índice, que marca BDC como obra em diálogo com outras gerações, é a narrativa ser dividida em duas partes, iniciadas por citações de Óscar Ribas, nos remetendo por duas vezes a palavra saudade; ao unir o plano drummondiano e o de Ribas, o autor acaba por evocar a saudade do futuro, tema tão caro às literaturas de língua portuguesa, já prenunciado por Arlindo Barbeitos em NZOJI (1978).

Além disto, Ondjaki angaria momentos delicados, reveladores do ambiente que permeia esta produção de percurso sinestésico, linguagem característica desse escritor, na acumulação (cf. GLISSANT, 2005) do pretérito imperfeito do verbo "a ver tudo em câmara lenta, como se fosse um filme a preto e branco:"(ONDJAKI, 2000, p. 120)

\begin{abstract}
Pela janela enorme entrava a luz, entrava o som dos passarinhos, entrava o som da água a pingar no tanque, entrava o cheiro da manhã, entrava o barulho das botas dos guardas da casa ao lado, entrava o grito do gato porque ele ia lutar com outro gato, entrava o barulho da despensa a ser aberta pela minha mãe, entrava o som de uma buzina, entrava uma mosca gorda, entrava uma libélula que nós chamávamos de helibélula, entrava o barulho do gato que depois da luta saltava para o telheiro de zinco, entrava o som do guarda a pousar a AK47 porque ia se deitar, entrava muita luz mas, acima de tudo, entrava o cheiro do abacateiro, o cheiro do abacateiro que estava a acordar. (ONDJAKI, 2000, p.84)
\end{abstract}

Como pudemos verificar anteriormente em Quem me dera ser onda, temos acima um olhar poetizado do espaço; em BDC, isto prevalece a maior parte da narrativa, mesmo quando o menino deixa transparecer suas primeiras impressões acerca do mundo-Luanda: "Ao passarmos por uns prédios muito feios, eu fiz adeus a uma camarada professora (...) ali é o bairro dos professores cubanos." (ONDJAKI, 2000, p.18).

\title{
4 Acumulando câmaras e câmeras
}

Quanto à construção estética das personagens, ressalta-se aqui o menino-narrador, uma Angola que cresce, na qual o autor se inscreve e se nomeia apenas uma vez durante a narrativa, todavia em terceira pessoa. Tal personagem inicia a obra com uma pergunta, através da conjunção adversativa: “-Mas, camarada António, tu não preferes que o país seja assim livre?" (ONDJAKI, 200, p. 15); como a nos lembrar outra conjunção, o histórico 'portanto' de PEPETELA ao iniciar o romance Geração Utopia (1994). Desta forma, o discurso marca e reafirma a continuidade, lingüisticamente, de uma nação literária. 
É na enunciação da personagem camarada António - cozinheiro na casa do narrador, vindo do Bié ${ }^{10}$, figura vital e sensível - que vemos uma possível alegoria da Angola antes de Independência,

- Ninguém era livre como assim? Era livre sim, podia andar na rua e tudo.... O camarada António aí ria só. Sorria com palavras, vendo-me assim entusiasmado dizia ' esse menino....!'(ONDJAKI, 2000, p.16-7)

Assim como, a presença de Tia Dada, que vive em Portugal e visita Luanda, pode-se entrever a Angola fora de Luanda, desvelando um pano de fundo de excessos das forças de segurança e a deferência para com o regime que marcam a cidade, filtrada na enunciação com ironia de adulto e ingenuidade do menino,

- Pois... escapaste é de ver a cerimônia de tiros que ia haver se algum FAPLA te visse a mexer, parecia que estavas a dançar, ainda por cima ias pôr o chapéu...

- Mas sempre que o presidente passa vocês têm que ficar em sentido? - ela estava mesmo espantada. (ONDJAKI,2000, p.58)

Um dos pontos de convergência entre as obras aqui analisadas é a imaginação imbricada através do olhar púbere, revelando uma sociedade de contrastes e sobreposições, em que há também a Angola, à margem de Luanda, aquela além da fronteira do asfalto, metaforizada na presença do menino Murtala, companheiro de escola, morador de musseque,

fui para baixo do telheiro e fiquei a ver a chuva cair. Lembrei-me imediatamente do Murtala : na casa dele, quando chove, só podem dormir sete de cada vez, os outros cinco esperam todos encostados na parede onde há um tectozinho que lhes protege. Depois é a vez dos outros dormirem, assim mesmo, juro, sete de cada vez. Sempre que chove de noite, o Murtala, no dia seguinte, dorme nos três primeiros tempos. (ONDJAKI,2000, p.43)

Também, a camaradagem entre as crianças, as estórias inventadas e aumentadas estão presentes durante toda a narrativa; por isso, principalmente na escola, quando se é absolutamente infiel ao contar um fato ocorrido e o interlocutor duvida, tem-se que afirmar: “tou-ta dizer, é verdade...”(ONDJAKI,2000, p.137). O mesmo ocorre, diversas vezes, como os meninos de Manuel Rui (2005b), de suas perspectivas aéreas, de meninos criados em prédios aglomerados, safam-se nas malandragens, 'macaqueando' o discurso político que também os atinge,

- A professora? Foi privilegiada do tempo do colono. Por isso é que é professora. Assim não custa dizer que só não estuda quem não quer.

- Por acaso a nossa professora veio do maquis. E estudou lá.

O homem ficou calado e de olhos no chão. Beto media-o de alto a baixo, feliz por tê-lo derrotado com aquela mentira. (RUI, 2005b, p. 58)

\footnotetext{
${ }^{10}$ Província angolana do centro-oeste.
} 


\section{Verzul}

Desta maneira, ao pensarmos a obra como uma superestrutura, nas últimas páginas de Bom dia camaradas, lemos o término de uma situação política: o fim de umas das fases da guerra civil é anunciado pela Rádio Nacional - ao som da chuva, o narrador vê cair as águas da fecundação sobre o quintal- jardim de sua casa, mesmo diante da solidão de quem tenta construir e sorrir sozinho, dá-se conta do ser- social cujas raízes já são profundas; com esse espírito, ao terminarmos a leitura de $B D C$ temos o título da obra a gritar um imenso vocativo à nação, à "água que faz eclodir um novo ciclo (...)” : “- Epá...e se chovesse aqui em Angola toda...?"(ONDJAKI, 2000, p. 144)

Da mesma forma, os meninos de Quem me dera ser onda, enquanto os pais e outros camaradas se refestelam com as partes já assadas do porco, após o desfile cívico nas tribunas, voltam ao prédio, a rês-do-chão,

Cá em baixo, os meninos confiavam na força da esperança para salvar ' carnaval da vitória'. E Ruca, cheio daquela fúria linda que as vagas da Chicala pintam sempre na calma do mar, repetiu a frase de Beto:

- Quem me dera ser onda! (RUI, 2005b, p.60)

As águas - sejam da chuva ou do mar - compõem motivos que dão corpo a ambos as obras, sobrepondo câmaras: casa, apartamento, rua, escola... partes da cidade que se erguem em pequenas poças de discurso utópico em uma cidade que sonha. Mesmo em suas margens, o discursus escorre em musseques como o Golf do camarada António: “ _ parece que a paz vai chegar menino...ontem tavam a falar lá no bairro..." (ONDJAKI, 2000, p.126) ou na praia de Carnaval da Vitória: "Zeca tinha voltado o olhar lá bem para o fundo dos contornos da Corimba. Território de ' carnaval da vitória'. Livre. Vadio na chafurda despreocupada.” (RUI, 2005b, p.55)

Luanda, como cidade de papel e letras, emerge sob o olhar de câmera, de máquina que fala, não só constrói -se como paisagem em levezas líricas ou em agudezas irônicas na relação dos possíveis sendo, compõe-se também de rastros e resíduos, "no viver com o outro e construir com ele, mas que estende suas ramificações em direção aos outros"(GLISSANT, 2005, p.154) e inocula-se na palavra camarada: a do espanhol dos cubanos, a do português dos angolanos, convergida da escrita à fala de Manuel Rui (2005a) e na dança das palavras quietas de Ondjaki (2006). 


\section{Referências}

ABDALA, Benjamin Jr. Literatura, História e Política. São Paulo: Ática, 1988. .De vôos e ilhas. São Paulo: Ateliê, 2003.

ANDRADE, Carlos Drummond. Obra completa. 2.ed. Rio de Janeiro:Aguilar, 1967.

BAKHTIN, Mikhail. Marxismo e filosofia da linguagem. São Paulo: HUCITEC, 1999.

BLOCH, Ernest. O princípio da esperança.Rio de Janeiro:Uerj, 2005.

CANDIDO, Antonio. O discurso e a cidade. 3.ed. Rio de Janeiro: Duas Cidades, 2004.

CUNHA, A.G. Dicionário etimológico da língua portuguesa.2.ed.Rio de Janeiro:Nova Fronteira, 1986.

GLISSANT, Edouard. Introdução a uma poética da diversidade. Rio de Janeiro: Ed. UFJF, 2005.

ONDJAKI. Bom dia camaradas. Luanda: Edições Chá de Caxinde, 2000. [Rio de Janeiro:Agir, 2006.

.Os da minha rua.Lisboa: Caminho, 2007.

.Oralidade e escrita: dançar com as palavras quietas. In.: Conferência do autor no Rhode Island College, EUA, abril, 2006.

PEPETELA. Geração Utopia. Rio de Janeiro: Nova Fronteira,1994.

RIBAS, Oscar. Cultuando as musas.s/r.,1992.

RUI, Manuel. Da escrita à fala. Separata. Ata do I congresso internacional de teoria da literatura e literaturas lusófonas. Coimbra: Almedina, 2005a.

Quem me dera ser onda. Rio de Janeiro: Griphus, 2005b. [Lisboa: Cotovia, 1982] 